\title{
COMPENSATION OF TEMPERATURE ERRORS WHEN MEASURING SURFACE TEXTURES BY APPLYING A TWO-DIMENSIONAL WAVELET TRANSFORM
}

\author{
W. Makiela ${ }^{*}$ J. Świderski $^{* *}$, D. Gogolewski ${ }^{* * *}$, K. Makiela $^{\dagger}$
}

\begin{abstract}
Fluctuations of the environmental temperature can affect significantly long-time measurements of surface textures using contact methods. This paper discusses an application of a two-dimensional wavelet transform to correct the temperature error for the case of contact measurements of surface texture.
\end{abstract}

Keywords: surface texture, stylus profilometer, wavelet decomposition

\section{Introduction}

The quality of a surface texture is one of key factors determining surface properties such as sliding abilities, lubrication, abrasion resistance, fatigue strength, thermal conductivity, corrosion resistance and tightness of connections. Therefore, it seems particularly important to identify potential sources of surface texture measurement errors and to correct systematic errors, that may influence measurement uncertainty.

Potential sources of errors in contact measurements of surface textures refer to the measuring instrument, the standard, environmental factors, properties of the measured element, software used to calculate the parameters and, of course, the operator conducting the measurement.

A $3 \mathrm{D}$ analysis is often used to evaluate the surface quality nowadays. The reason is that measuring a single profile does not provide a full information about the characteristics of the surface texture of the analyzed object. Contact methods, among others, are often used to perform 3D measurements of the surface texture. These methods are based on reconstructing the 3D view of the surface from 2D profiles.

The main disadvantage of contact methods is long time needed to conduct a measurement. This time is dependent on the size of the measured area, moving speed of the stylus tip along X-axis that is perpendicular to the machining trace as well as on the sampling interval along $\mathrm{Y}$-axis.

Requirements and limitations arising from the conditions for contact measurements influence the time needed to measure surface textures. A single measurement may take from several dozen minutes even up to a few hours. As it has been shown in the conducted experiments, during such long measurements the environmental temperature fluctuations may affect the measuring device and are not negligible. In laboratory conditions such fluctuations can be caused by operation characteristics of an air conditioning equipment (periodical fluctuations of the temperature equal to the amplitude value, which are due to precision of air conditioning). The impact of periodical fluctuations of the environmental temperature on the results of surface stereometry measurement is presented using a flat interference plate. Surface

\footnotetext{
Włodzimierz Makieła, .: Faculty of Mechatronics and Mechanical Engineering, Kielce University of Technology, Al. Tysiąclecia Państwa Polskiego 7; 25-314, Kielce; PL, wmakiela@tu.kielce.pl

** Jacek Świderski, .: Faculty of Mechatronics and Mechanical Engineering, Kielce University of Technology, Al. Tysiąclecia Państwa Polskiego 7; 25-314, Kielce; PL, swiderski@tu.kielce.pl

*** Damian Gogolewski, .: Faculty of Mechatronics and Mechanical Engineering, Kielce University of Technology, Al. Tysiąclecia Państwa Polskiego 7; 25-314, Kielce; PL, dgogolewski@tu.kielce.pl

$\dagger \quad$ Kamil Makieła,: Department of Econometrics and Operations Research, Cracow Univesrity of Economics, Rakowicka 27, Kraków; PL, makielak@uek.krakow.pl
} 
isometric view, Y-axis, shows a distinctive component of waviness (Fig.1a). This waviness component is highly correlated with the environmental temperature (Fig.1b) (Miller, 2017).

a)

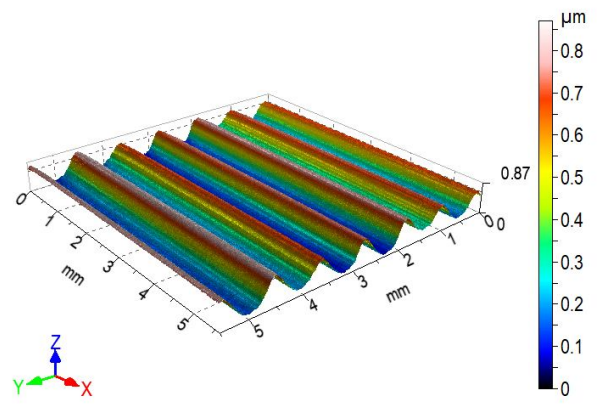

b)

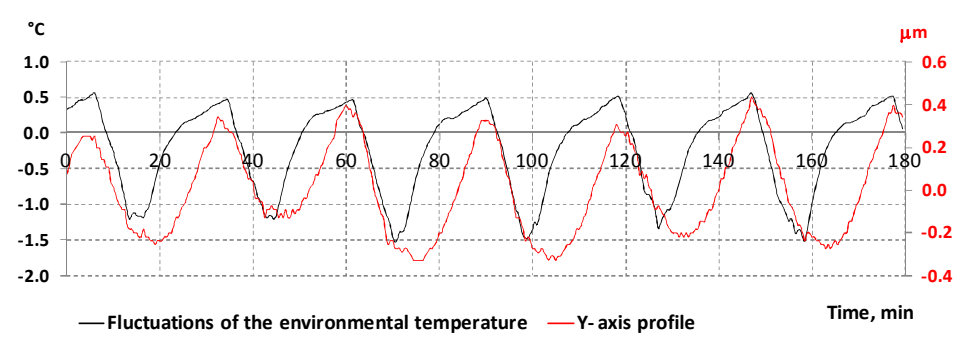

Fig. 1: a) Isometric view, b) Y-axis profile and fluctuations of the environmental temperature

Waviness component shown in the picture, Y-axis, is a systematic error of a surface texture measurement. The impact of this component on the values of surface texture parameters can be mitigated by filtering the component out.

Traditional methods for separating individual components of a surface texture are based on Gaussian filter. This type of filtration has been used in the paper as a reference method for removing measurement errors resulting from fluctuations of the environmental temperature. Its results are compared to other methods proposed in the paper.

Scientists at Kielce University of Technology have been actively developing methods that apply a twodimensional wavelet transform to analyze surface texture for several years now (Makieła, 2014, 2015, 2016; Stępień, 2014). The paper presents application capabilities of a two-dimensional wavelet transform. The following types of mother wavelets have been used to correct the environmental temperature error: Coiflet, Daubechies and Symlet.

\section{Methods}

Wavelet transform is a relatively new tool for measurement signal analysis. One of its areas of application is concerned with filtering signals, which represent irregularities of the surface texture of machine parts. There are numerous papers that show applications of one-dimensional wavelet functions in filtering and decomposing roughness profiles, i.e. the so-called 2D profile (Zawada-Tomkiewicz, 2010). Evaluation of these profiles is mainly used to diagnose machining processes and to assess quality of the machined surface. Due to the reasons mentioned earlier there is currently a demand for analyzing surface texture signals, i.e. 3D signals. A two-dimensional wavelet transform seems to be the most adequate method for this task. A discrete two-dimensional wavelet transform is defined via Equations $(1,2)$ :

$$
\begin{gathered}
W_{\varphi}\left(j_{0}, m, n\right)=\frac{1}{\sqrt{M N}} \sum_{x=0}^{M-1} \sum_{y=0}^{N-1} f(x, y) \varphi_{j_{0}, m, n}(x, y) \quad m, n=0,1,2, \ldots, 2^{j}-1 \\
W_{\phi}^{i}\left(j_{0}, m, n\right)=\frac{1}{\sqrt{M N}} \sum_{x=0}^{M-1} \sum_{y=0}^{N-1} f(x, y) \phi_{j_{0}, m, n}^{i}(x, y) \quad i=\{h, v, d\}
\end{gathered}
$$

where:

$f(x, y)$ - is the two-dimensional function with dimensions of $M x N$,

$W_{\varphi}\left(j_{0}, m, n\right)-$ is the approximation signal,

$W_{\varphi}^{i}\left(j_{0}, m, n\right)$ - is the details signal,

$\varphi(x, y)$ - is the two-dimensional scaling function,

$\phi(x, y)$ - is the two-dimensional mother wavelet. 


\section{Measurement results}

Measurements have been conducted using contact profilometer Form Talysurf PGI 1200. It uses interferometer head with measurement range of $12.5 \mathrm{~mm}$ and a resolution of $0.8 \mathrm{~nm}$. This allows us to measure surface texture in respect to waviness and roughness profiles. The surface being measured is an area of $6 \mathrm{~mm} \times 6 \mathrm{~mm}$ from the bearing raceway with periodical fluctuations of the temperature of amplitude equal $0.5 \mathrm{C}$. Fig.2a shows surface isometric view of the bearing raceway once its nominal shape is removed but the temperature error component is still included. Impact of periodical fluctuations of the temperature on the conducted measurement can be viewed via the extracted profile, $\mathrm{Y}$-axis (Fig.2b).

a)

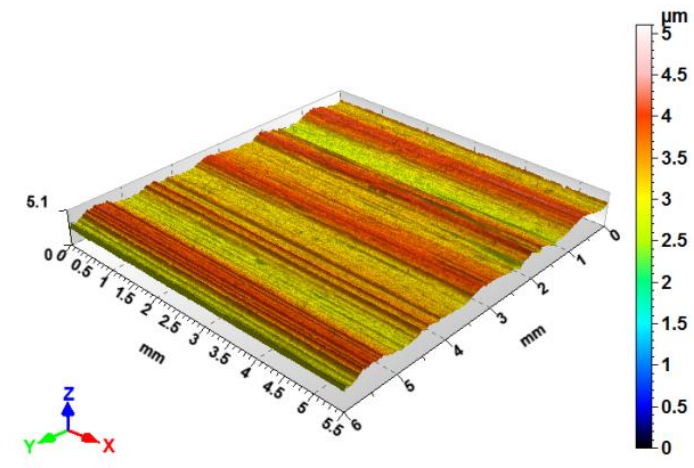

b)

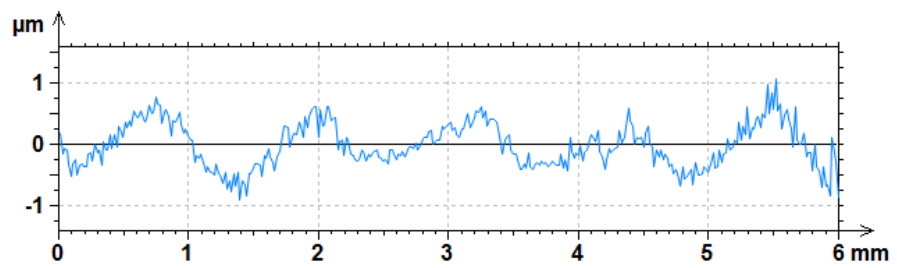

Fig. 2:a) Isometric view, b) Y-axis profile

In order to remove the component being an effect of periodical fluctuations of the environmental temperature the following types of signal filtration methods have been used:

- Gaussian filter $\lambda \mathrm{c}=0.25 \mathrm{~mm}$.

- Two-dimensional wavelet transform, Coiflet (scale 1 to 5).

- Two-dimensional wavelet transform, Daubechies (scale 1 to 10).

- Two-dimensional wavelet transform, Symlet (scale 1 to 8).

Figure 3 shows the surface of the bearing raceway after applying Gaussian filter and a two-dimensional wavelet transform (Coiflet mother wavelet).

a)

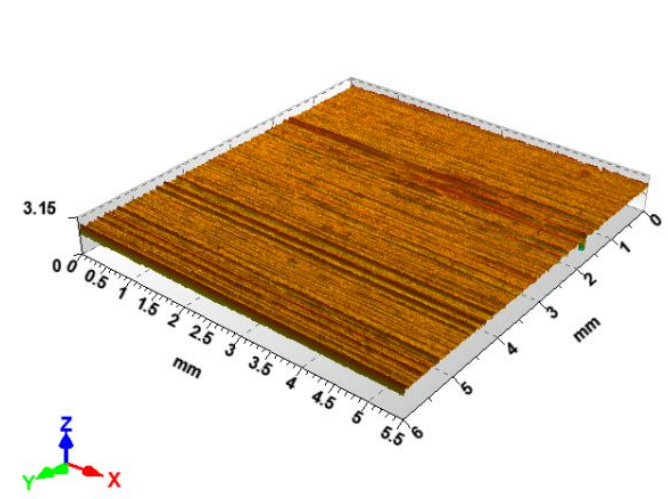

b)

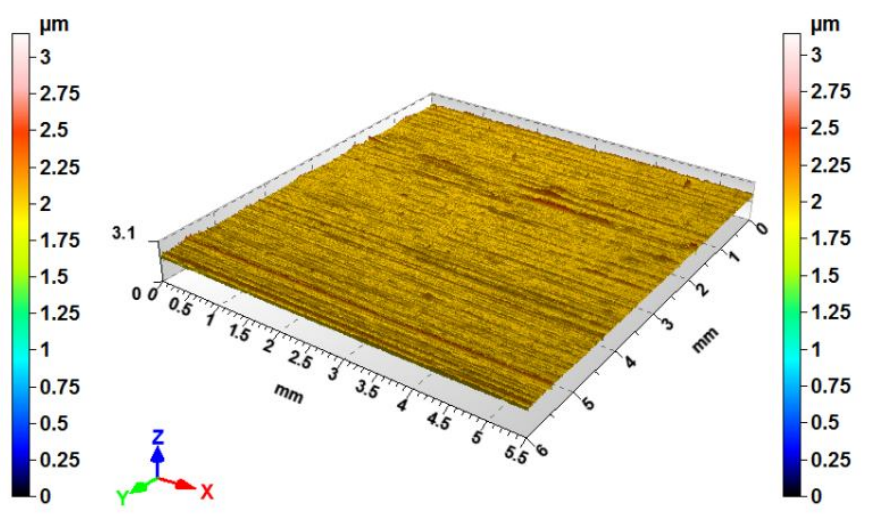

Fig. 3: Isometric view a) Gaussian filter applied $\lambda c=0.25 \mathrm{~mm}$ b) two-dimensional wavelet transform applied (Coiflet mother wavelet)

Table 1 shows values of amplitude parameters for the measured surface in the case of original surface (no filtration), after applying Gaussian filter $(\lambda \mathrm{c}=0.25 \mathrm{~mm})$ and after applying a two-dimensional wavelet transform with different mother wavelets for the first level of decomposition of the input signal. 
Tab. 1: Values of the amplitude parameters

\begin{tabular}{|c|c|c|c|c|c|c|}
\hline & Parameter / Unit /Name & $\begin{array}{l}\text { Primary } \\
\text { surface }\end{array}$ & $\begin{array}{c}\text { Gaussian } \\
\text { filter } \\
\lambda \mathrm{c}=\mathbf{0 , 2 5} \\
\mathrm{mm} \\
\end{array}$ & $\begin{array}{l}\text { Coilflet } \\
\text { mother } \\
\text { wavelet }\end{array}$ & $\begin{array}{c}\text { Daubechies } \\
\text { mother } \\
\text { wavelet }\end{array}$ & $\begin{array}{l}\text { Symlet } \\
\text { mother } \\
\text { wavelet }\end{array}$ \\
\hline$S q$ & $\mu \mathrm{m}$ Root mean square height & 0.37 & 0.12 & 0.10 & 0.10 & 0.11 \\
\hline Ssk & Skewness & -0.06 & -1.30 & -0.30 & -0.25 & -0.37 \\
\hline Sku & Kurtosis & 3.10 & 15.00 & 8.08 & 7.76 & 8.21 \\
\hline$S p$ & $\mu \mathrm{m}$ Maximum peak height & 1.70 & 0.94 & 1.04 & 1.15 & 1.05 \\
\hline Sv & $\mu \mathrm{m}$ Maximum pit height & 3.40 & 2.20 & 1.64 & 1.48 & 1.45 \\
\hline$S z$ & $\mu \mathrm{m}$ Maximum height & 5.10 & 3.20 & 2.66 & 2.63 & 2.51 \\
\hline$S a$ & $\mu \mathrm{m}$ Arithmetic mean height & 0.31 & 0.08 & 0.07 & 0.08 & 0.08 \\
\hline
\end{tabular}

The obtained values of surface texture parameters for S-F type surface (surface after removing its nominal shape ) and S-L type surface (surface after applying Gaussian filter) differ substantially. In this case Gaussian filter should not be regarded as a way for removing the waviness component but rather as a correction of the temperature error. The values of surface texture parameters acquired using the twodimensional wavelet transform are very similar to each other regardless of the mother wavelet used. Parameters Ssk and $S k u$ are the ones the most sensitive to the choice of the temperature error filtration method.

\section{Conclusions}

The temperature error occurs during surface texture measurements with contact methods due to periodical fluctuations of the environmental temperature. The analysis indicates that the use of a two-dimensional wavelet transform to correct such an error may be a good alternative to Gaussian filter.

The results are encouraging and further research on wavelet transform applications should be pursued. Future studies should focus on the use of other mother wavelets and assessing the impact of wavelet decomposition level on the parameters and their values.

\section{Acknowledgements}

The study constitutes a part of the project contract by Polish National Centre of Research and Development no. PBS2/A6/20/2013/NCBiR/24/10/2013;

"Research and evaluation of reliability of modern methods of surface topography measurements in micro and nano scale".

\section{References}

Makieła, W., Gogolewski, D. Badania wpływu transformaty falkowej na parametry stereometrii powierzchni, Pomiary Automatyka Kontrola, Vol. 09/2014, pp. 709-712

Makieła, W., Gogolewski, D. Ocena zmienności zarysów stereometrii powierzchni w procesie dekompozycji falkowej za pomocą testu T2 Hotellinga, Mechanik, Vol. 8-9/2015, pp. 559-567

Makieła, W., Gogolewski, D.: Zastosowanie dwuwymiarowej transformaty falkowej do oceny chropowatości powierzchni frezowanych, Mechanik, Vol. 11/2016 pp.1627-1629

Miller, T., Adamczak, S., Świderski, J., Wieczorowski, M., Łętocha, A., Gapiński, B. Influence of temperature gradient on surface texture measurements with the use of profilometry, Bulletin of the Polish Academy of Sciences-Technical Sciences, pp. 53-61 (2017)

Stępień, K., Research on a surface texture analysis be digital signal processing method, Tehnicki Vjesnik Technical Gazette, Vol. $21 \mathrm{nr}$ 3/2014, pp. 485-493

Zawada-Tomkiewicz, A. Estimation of surface roughness parameter based on machined surface image, Metrology and Measurement Systems, Vol. XVII, nr 3/2010 pp.493-504 